A real impediment to the successful treatment of tuberculosis is the development of severe adverse drug reactions, and patients with concurrent HIV infection seem to be particularly at risk. This is shown in our study by the occurrence of Stevens-Johnson syndrome exclusively in patients positive for HIV. It has been widely speculated that thiacetazone is the drug responsible for most of these serious rashes, ${ }^{14} 15$ but this is not yet proved. Hypersensitivity to any antituberculous drug may cause a rash, and studies in which treatment did not include thiacetazone have also shown a greater incidence of adverse drug reactions among patients positive for HIV. ${ }^{16}$ If, however, it is true that one drug is responsible for most drug reactions then it should be clearly identified so that its use in patients positive for HIV may be avoided.

Another outstanding practical question regarding the management of tuberculosis in the presence of HIV infection is whether, as seems likely, the immune deficiency caused by the virus leads to a greater danger of relapse. Current evidence is preliminary and conflicting. ${ }^{910} 17$ No difference in HIV prevalence was observed in our study between relapsed and new cases. A more appropriate comparison, however, is between patients who have had tuberculosis and have or have not relapsed; further studies of this kind are needed. As well, prospective studies are needed to discover whether tuberculosis causes an increased rate of progression to AIDS and whether the prophylactic use of antituberculous drugs in asymptomatic patients positive for tuberculin and HIV can increase their span of healthy life.

Serum samples were analysed by $\mathrm{Mr}$ Joseph Syambango and the staff of the University Teaching Hospital immunology laboratory and the sputum samples by $\mathrm{Mr} \mathrm{K}$ Namaambo and the staff of the Chest Diseases Laboratory, Chelston, Lusaka. The study was supported by the Commission of the European Communities, contract TS2.004.UK(H). Further assistance was received from Barclays Bank of Zambia and the commercial community in Lusaka; equipment was provided at low cost by the Joint Mission Hospital Equipment Board.

1 Tuberculosis and acquired immunodeficiency syndrome-New York City. $M M W R$ 1987;36:785-95.

Slutkin G, Leowski J, Mann J. The effect of the AIDS epidemic on the tuberculosis problem and tuberculosis programmes and priorities for control and research. Bull Int Union Tuberc L ung Dis 1988;63:21-4.

3 Legg W, Mahari M, Houston S, Neill P, Ray C, Marowa E. Association of tuberculosis and HIV infection in Zimbabwe [Abstract]. In: Fifth international conference on AIDS, Montreal, 1989. Ottawa: International Development Research Centre, 1989

4 Colebunders R, Ryder R, Nzilambi N, et al. HIV infection in patients with tuberculosis in Kinshasa, Zaire. Am Rev Respir Dis 1989;139:1082-5.

Blaser MJ, Cohn DL. Opportunistic infections in patients with AIDS: clues to the epidemiology of AIDS and the relative virulence of pathogens. Rev Infect Dis $1986 ; 8: 21-30$.

6 Roselgaard E, Iversen E, Blocher C. Tuberculosis in tropical Africa. An epidemiological study. Bull WHO 1964;30:459-518.

7 Breslow NE, Day NE. Statistical methods in cancer research. Vol 2. The analysis of case-control studies. Lyons: International Agency for Research on Cancer, 1980.

8 Luo NP, Dallas ABC, Chipuka L, Nshimbi R, Tedder R, Siyambango J. HIV seroprevalence amongst healthy blood donors in 31 hospitals in Zambia [Abstract]. In: Fifth intermational conference on AIDS, Montreal, 1989. Otrawa: International Development Research Centre, 1989.246.

9 Chaisson RE, Schecter GF, Theuer CP, Rutherford GW, Echenberg DF, Hopewell PC. Tuberculosis in patients with the acquired immunodeficiency syndrome. Am Rev Respir Dis 1987;136:570-4.

0 Perriens J, Karahunga C, Willame J, Kaboto M, Pauwels P, Colebunders R. Mortality, treatment results and relapse rates of pulmonary tuberculosis in African HIV $(+)$ and HIV $(-)$ patients [Abstract]. In: Fifth international conference on AIDS, Montreal, 1989. Ottawa: International Development Research Centre, 1989:193.

11 Revision of the CDC surveillance case definition for acquired immunodeficiency syndrome. $M M W R$ 1987;36(suppl):3-16S.

12 Pitchenik AE, Rubinson HA. The radiographic appearance of tuberculosis in patients with the acquired immunodeficiency syndrome (AIDS) and preAIDS Am Reo Respir Dis 1985;131:393-6.

13 Acquired Immunodeficiency Syndrome (AIDS). WHO/CDC case definition for AIDS. Weekly Epidemiological Record 1986;61:69-76.

14 Tuberculosis and AIDS. Statement on AIDS and tuberculosis. Geneva: March 1989. Bull Int Union Tuberc Lung Dis 1989;64:8-11.

15 Pinching AJ. Prophylactic and maintenance therapy for opportunistic infections in AIDS. AIDS 1988;2:335-43.

16 Soriano E, Mallolas J, Gatell JM, et al. Characteristics of tuberculosis in HIVinfected patients: a case-control study. AIDS 1988;2:429-32.

17 Sunderam G, Mangurs BT, Lombardo JM, Reichman LB. Failure of 'optimal' short-course chemotherapy in a compliant patient with human immunodeficiency virus. Am Rev Respir Dis 1987;136:1475-8.

(Accepted 13 fune 1990)

\title{
Terminal cancer care and patients' preference for place of death: a prospective study
}

Joy Townsend, A O Frank, David Fermont, Sandra Dyer, Olive Karran, Anne Walgrove, Mary Piper

Abstract

Objective-To assess the preference of terminally

MRC Epidemiology and Medical Care Unit, Northwick Park Hospital, Harrow HA1 3UJ

Joy Townsend, MSC, scientific staff

Sandra Dyer, MSC, scientific staff

Olive Karran,

administrative staff

Anne Walgrove, SRN, nursing staff

Northwick Park Hospital, Harrow HA1 3UJ

A O Frank, FRCP, consultant, rehabilitation medicine

David Fermont, FRCR, consultant oncologis

Mary Piper, FRCP,

consultant, geriatric medicine

Correspondence to: Mrs Townsend.

BrMed f 1990;301:415-7 ill patients with cancer for their place of final care.

Design-Prospective study of randomly selected patients with cancer from hospital and the community who were expected to die within a year. Patients expected to live less than two months were interviewed at two week intervals; otherwise patients were interviewed monthly. Their main carer was interviewed three months after the patient's death.

Setting-District general hospital, hospices, and patients' homes.

Main outcome measure-Stated preferred place of final care; actual place of death; reason for final hospital admission for those in hospital; community care provision required for home care.

Results-Of 98 patients approached, 84 $(86 \%)$ agreed to be interviewed, of whom $70(83 \%)$ died during the study and $59(84 \%)$ stated a preferred place of final care: $34(58 \%)$ wished to die at home given existing circumstances, $12(20 \%)$ in hospital, $12(20 \%)$ in a hospice, and one (2\%) elsewhere. Their own home was the preferred place of care for 17 (94\%) of the patients who died there, whereas of the 32 patients who died in hospital $22(69 \%)$ had stated a preference to die elsewhere. Had circumstances been more favourable $67 \%$ (41) of patients would have preferred to die at home, $16 \%(10)$ in hospital, and $15 \%(9)$ in hospice.

Conclusion - With a limited increase in community care $50 \%$ more patients with cancer could be supported to die at home, as they and their carers would prefer.

\section{Introduction}

Place of death and quality of final care are important components of terminal cancer care for both the patient and the family. The proportion of patients with cancer dying at home has fallen steadily in the United Kingdom, from $37 \%$ in 1965 to $27 \%$ in $1987 .{ }^{1}$ In Edinburgh and Western Australia, however, the provision of cancer care services has enabled as many as $41 \%$ and $70 \%$ respectively of patients with cancer to die at home. ${ }^{23}$ There are no studies in the United Kingdom reporting patient preferences about place of terminal care.

This study was therefore undertaken to determine prospectively the needs and wishes of patients who were dying from cancer, their symptoms and symptom 
relief, ${ }^{4}$ where they wished to die, and the resources required for their home and hospital care.

\section{Patients and methods}

Patients were referred to the study from Northwick Park Hospital and local community nursing services between August 1986 and September 1987. The pathology, haematology, and cytology departments of the hospital routinely informed us of patients diagnosed as having cancer, and those whom the consultant thought likely to live for less than one year were identified as eligible for the study. A random sample $(50 \%$ reducing to $25 \%$ towards the end of the study, when interviewer time was limited) were approached for interview.

Patients who were considered by the medical team in charge of their care to have less than two months to live were interviewed at fortnightly intervals; otherwise interviews were monthly. The interviewer, who was experienced in interviewing the dying and bereaved, travelled to the patient on all occasions.

A specially devised structured questionnaire was used. The patient's view of his or her illness was sought by asking specific questions such as, "Tell me something about the progress of your illness." Further questions concerned use of health and social services, medication, care in the home, availability of care, activities of daily living, and mobility. ${ }^{4}$ Quality of life and level of pain and other symptoms were assessed. ${ }^{56}$ Patients were then asked, "Do you have any plans for your future care?" and "What would you like for your future care were it possible?" and also if they were content in their present place of care. If a clear answer was not forthcoming a range of possible alternatives was given, including "Would you like to go to hospital; go home; go to a friend, or stay as at present?" If these questions did not elicit the preferred place of death, and the patient had already acknowledged the diagnosis and prognosis, further questions were put such as, "And if your illness gets worse, where would you like to be?" The aim was to determine preferences for place of final care, firstly, given the existing situation and, secondly, if circumstances were instituted to allow the choice. We acknowledged the sensitivity of this area of questioning and it was with this in mind that the questions were put and the interviews conducted. The answer was used in analysis of data only if an unambiguous response was made.

Carers of the patients who died in the first half of the study were interviewed for their assessment of the patient's care. These interviews took place three months after the death of their relative.

Inpatient stay in Northwick Park Hospital was monitored for all patients in the study, whether interviewed or not. Those interviewed were asked about the community support received at the time of admission, and the resources needed for the patient to be discharged home were assessed. Patients were monitored until the end of the study on 1 February 1988.

\section{Results}

Of the 230 patients referred to the study, 98 were randomly selected to be approached for interview and 84 agreed to be seen. Forty four were men and 40 women. Eight patients or their families declined, and six patients were not interviewed for other reasons.

The median number of interviews was three (range 1-15). Six patients declined further interview in the later stages of their illness. Seventy of the interviewed patients (83\%) died during the period of the study, 39 of whom $(56 \%)$ were interviewed within the last 14 days of their life. The distribution of cancer sites in patients in the study was not significantly different from the national distribution. ${ }^{7}$ Sixty seven $(80 \%)$ of the patients interviewed lived with one or more people, $16(19 \%)$ lived alone, and one (1\%) lived in an old people's home.

Among the 51 patients with a principal carer, the carer of 39 was a spouse $(76 \%)$, of seven a son or daughter $(14 \%)$, of three another relative $(6 \%)$, and of two a friend (4\%). At least $16(31 \%)$ of the principal carers were in bad health. Fifteen $(29 \%)$ were aged over 70 and $33(65 \%)$ were over 60 . The distribution of place of death in the study was similar to the national figures for all patients dying from cancer in Britain (table I). ${ }^{\text {? }}$

Of the 70 patients who died during the study, 59 $(84 \%)$ said on at least one occasion where they would prefer to die given existing circumstances. A further two patients said only where they would prefer to die given ideal circumstances. Six did not acknowledge their diagnosis or prognosis, and the remaining three knew their diagnosis but not their immediate prognosis.

The initial choice of those stating a realistic preference for place of death was $58 \%$ (34) at home, $20 \%$ (12) in hospital, $20 \%$ (12) in a hospice, and one (2\%) elsewhere (table II). The choice stated finally was $49 \%$ (29) at home, $24 \%(14)$ in hospital, and $25 \%$ (15) in a hospice. The change in preference was not of a significant order but tended to be towards hospital or hospice-probably reflecting, given the resources available at the time, a realistic response to pressure on carers as the illness progressed. The preferences given ideal circumstances moved the other way, from $67 \%$ (41) to $70 \%$ (43) preferring home, $16 \%$ (10) to $10 \%$ (6) hospital, and $15 \%(9)$ to $18 \%$ (11) hospice.

Of the 32 who died in hospital, $20(63 \%)$ had stated a final preference to die elsewhere, whereas for the 18 who died at home this was the chosen place for 17 (94\%). Hospice was the preferred place for seven $(78 \%)$ of the nine who died there.

Answers to the questions on future plans were often quite explicit, such as "I hope to go home and will make arrangements to go to a hospice for the end"; "I want to stay at home till the end"; "I have to stay here in hospital while on the antibiotics, then the doctor says I can go home-I'd rather stay here in hospital, but I'm afraid they'll need the bed.'

Of the 30 carers who were interviewed three months after the death of their relative and stated an opinion on where he or she had died, $21(70 \%)$ were satisfied. Five carers $(28 \%)$ of the 18 patients who died in hospital would have preferred to have cared for them at home. Of the 11 carers whose relatives died at home, seven were satisfied; three accepted the patient's wish to die at home, although they thought they would have been

TABLE I-Deaths from cancer in study and in England and Wales by place of death. Values are percentages (numbers)

\begin{tabular}{lcc}
\hline Place of death & Study $^{\star}(1986-8)$ & $\begin{array}{c}\text { England and Wales } \\
(1987)\end{array}$ \\
\hline Home & $29(20)$ & 27 \\
NHS hospital & $57(40)$ & 56 \\
Elsewhere & $14(10) \dagger$ & $17 \neq$ \\
Hospice† & $14(10)$ & $\dagger$ \\
Total & $100(70)$ & \\
\hline
\end{tabular}

${ }^{\star}$ Place of death as given on death certificates.

†Deaths in hospices $\ddagger$ Proportion of deaths in hospices not known.

TABLE II - Actual place of death of patients with cancer and preferred place of death, given existing circumstances, as stated in interview

\begin{tabular}{lcccc}
\hline & \multicolumn{5}{c}{ Initial (final) preferred place } \\
\cline { 2 - 5 } Actual place & Home & Hospital & Hospice & Other \\
\hline Home $(\mathrm{n}=18)$ & 17 & 1 & & \\
Hospital $(\mathrm{n}=32)$ & $15(11)$ & $10(12)$ & $6(5)$ & 1 \\
Hospice $(\mathrm{n}=9)$ & $2(1)$ & 1 & $6(7)$ & \\
\hline Total $(\mathrm{n}=59)$ & $34(29)$ & $12(14)$ & $12(15)$ & 1 \\
\hline
\end{tabular}


TABLE III - Requirements to permit patient to die at home, assessed during last stay in hospital (median time to death 13 days). Values are numbers (percentages)

\begin{tabular}{lccccc}
\hline & \multicolumn{5}{c}{ Requiring and } \\
Service & $\begin{array}{c}\text { No patients } \\
\text { assessed }\end{array}$ & $\begin{array}{c}\text { Rot yet receiving Already receiving } \\
\text { service }\end{array}$ & $\begin{array}{c}\text { Requiring more } \\
\text { service }\end{array}$ & $\begin{array}{c}\text { Service not } \\
\text { of service }\end{array}$ & needed \\
\hline Macmillan nurse & 53 & $37(70)$ & $6(11)$ & $5(9)$ & $5(9)$ \\
Special mattress & 51 & $33(65)$ & $2(4)$ & $1(2)$ & $15(29)$ \\
Other aids & 49 & $30(61)$ & $2(4)$ & $4(8)$ & $13(27)$ \\
District nurse & 53 & $32(60)$ & $1(2)$ & $15(28)$ & $5(9)$ \\
24 Hour care & 53 & $19(36)$ & $2(4)$ & $6(11)$ & $33(62)$ \\
Home care worker & 52 & $28(54)$ & $16(31)$ \\
Night check & 52 & $16(31)$ & $1(2)$ & $1(2)$ & $35(67)$ \\
Day centre & 53 & $14(26)$ & $2(4)$ & & $38(72)$ \\
Respite care & 53 & & & & $51(96)$ \\
\hline
\end{tabular}

better in hospital; and one would have preferred hospital but there had been no time to arrange for admission.

Comments on hospital care were made by 23 patients. Many were favourable, but others reflected the problems of caring for dying patients on acute wards and confirmed other reports. ${ }^{8} 1012-14$ Difficulties in communication between hospital staff and patient or family and between hospital and community services were stated. Patients or relatives said that on occasions promises were made about the availability of community support but they did not materialise. The position of the bed in the ward not infrequently created difficulties. Patients were often at the less supervised end of the ward and were sometimes overlooked for periods of an hour or more. Some were disturbed by noisy patients, and others were very lonely in a side ward. There was a recurrent theme of inadequate facilities for families visiting dying relatives, including lack of privacy, accessibility of food, and overnight facilities. Several families related problems about not being advised of the likely imminence of death within the next day or so. Although this may reflect the difficulty of making this judgment, it seems clear that some hospital staff may not have been aware of the importance of this issue to relatives. As well as their anxieties about the illness, many patients and their families had financial problems, including problems with paying for necessary prescriptions, special food, and heating.

Of the 79 patients who died before the end of the study (including nine not interviewed), $42(53 \%)$ died in Northwick Park Hospital; reasons for admission were known for $30(71 \%)$. Ten $(33 \%)$ were admitted for terminal care, nine $(30 \%)$ for management of symptoms, nine for investigation, and two for specific treatment (radiotherapy and chemotherapy). Only a few needed the resources of an acute care ward.

An assessment was made during their last stay in hospital of the requirements of patients to enable them to be cared for at home (53 patients; table III). This showed that less than $40 \%$ (19) needed 24 hour care but indicated the need for more short term care from the district nursing and home care services, as well as support from a continuing care (Macmillan) nurse.

\section{Discussion}

A very high proportion of patients, over $90 \%$, were aware of their diagnosis, and at least $95 \%$ of these knew their long term if not their immediate prognosis. Thus, many more patients than we had expected were informed and prepared to state their preference for place of final care. Most patients were admitted for investigation or treatment but often stayed for respite and symptom control. Few admissions were for pain control. In some patients the disease progressed too rapidly to allow community support to be mobilised easily. Of those who died in hospital, $63 \%$ had stated a last preference to die elsewhere and $82 \%$ would ideally have preferred to die elsewhere. It would not be practicable for all those dying in hospital to return home, and neither would this be their wish or that of their carers. ${ }^{8}$ Half of the patients, however, would have preferred to be at home, and $28 \%$ of carers of those dying in hospital also wished for them to be at home.

It was assessed that nearly two thirds of the patients in hospital for the last admission did not need 24 hour care but could have been looked after adequately with the support of visits from the continuing care and district nursing services, short term use of equipment such as a pressure relieving mattress when needed, and some home care support. It is estimated that over a quarter of those dying in hospital had a carer willing to care for them at home and wished for this option, which would have been possible with fairly limited flexible short term support from health and social services. This suggests that, including the $29 \%$ of patients who died at home and for whom this was their and their carers' place of choice, $44 \%$ of patients could have been supported to die at home.

The abolition of a qualifying period for attendance allowance, effective from November, has been proposed for those who are terminally ill. It is hoped that this will alleviate some of the financial anxieties of many such patients and their carers.

Some expansion of health and social service community support for the terminally ill is needed to facilitate policies for those who wish to die at home. ${ }^{910}$ In recognition of this, Harrow Health Authority has now considerably increased community nursing for the dying to include a small team of four Macmillan nurses, a nurse "sitting" service, and provision of equipment. There are at present not as many hospice beds as patients would like, and there is a need for complementary hospital care, ${ }^{8112}$ such as a small unit of 12 to 15 beds to support the community team, run on a hospice basis ${ }^{13-16}$ to provide necessary inpatient palliative and terminal care, including provision for relatives. This would alleviate some of the inevitable problems of caring for dying patients on a busy acute ward..$^{81012}$ The cost would be considerably less than that of the acute beds used at present.

Many colleagues from Harrow district and neighbouring districts helped in the study, which was funded by Harrow Health Authority and the Rehabilitation Research Fund. We thank Jacqueline Cooper for help with computing.

1 Ford GR, Pincherle G. Arrangements for terminal care in the NHS (especially those for cancer patients). Health Trends 1978;10:73-6

2 Doyle D. Domiciliary terminal care: demands on statutory services. $f \mathrm{R}$ Coll Gen Pract 1982;32:285-91.

3 Allbrook D. Dying of cancer-home, hospice or hospital. Med f Aust 1984;141:143-4.

4 Townsend J, Dyer S, Karran O, et al. Continuing and terminal care in Harrow: a report on resource requirements by a working party to the Harrow Health Authority. Harrow: MRC Epidemiology and Medical Care Unit, 1988.

5 Spitzer WO, Dobson AJ, Hall J, et al. Measuring the quality of life of cancer patients: a concise QL index for use by physicians. I Chronic Dis 1981:34:585-97.

6 Morris JN, Suissa S, Sherwood S, Wright SM, Greer D. Last days: a study of the quality of life of terminally ill cancer patients. I Chronic Dis $1986 ; 39: 47-62$.

7 Office of Population Censuses and Surveys. Mortality statistics for 1987. England and Wales. London: HMSO, 1989

8 Hockley JM, Dunlop R, Davies RJ. Survey of distressing symptoms in dying patients and their families in hospital and the response to a symptom contro team. Br Med f 1988;296:1715-7.

9 National Association of Health Authorities. Care of the dying-a guide for health authorities. Birmingham: NAHA, 1987.

10 Subcommittee on Cancer. Terminal care: report of a working group. London: HMSO, 1981. (E Wilkes, chairman.)

11 Cartwright A, Hockley L, Anderson JL. Life after death. London: Routledge and Kegan Paul, 1973.

12 Bates T, Clarke D, Hoy AM, Laird PP. The St Thomas's Hospital terminal care support team. A new concept in hospice care. Lancet 1981;i:1201-3.

13 Hoskin PJ, Hanks GW. The management of symptoms in advanced cancer: Hoskin PJ, Hanks GW. The management of symptoms in advanced cancer:
experience in a hospital-based continuing care unit. $f R$ Soc Med $1988 ; 81: 341-4$

14 Parkes CM. The dying patient. Terminal care: home, hospital or hospice? Lancet 1985;i:155-7.

15 Saunders C, Summer DH, Teller N. Hospice: the living idea. London: Edward Arnold, 1981

16 Rees WD. Role of the hospice in the care of the dying. Br Med $f$ 1982;285: $1766-8$

(Accepted 26 fune 1990) 